NASA/TM-2010-216255

\title{
An Extension of Analysis of Solar-Heated Thermal Wadis to Support Extended-Duration Lunar Exploration
}

R. Balasubramaniam

National Center for Space Exploration Research, Glenn Research Center, Cleveland, Ohio

S.A. Gokoglu and K.R. Sacksteder

Glenn Research Center, Cleveland, Ohio

R.S. Wegeng

Pacific Northwest National Laboratory, Battelle Memorial Institute, Richland, Washington

N.H. Suzuki

Headquarters, Washington, DC 


\section{NASA STI Program . . . in Profile}

Since its founding, NASA has been dedicated to the advancement of aeronautics and space science. The NASA Scientific and Technical Information (STI) program plays a key part in helping NASA maintain this important role.

The NASA STI Program operates under the auspices of the Agency Chief Information Officer. It collects, organizes, provides for archiving, and disseminates NASA's STI. The NASA STI program provides access to the NASA Aeronautics and Space Database and its public interface, the NASA Technical Reports Server, thus providing one of the largest collections of aeronautical and space science STI in the world. Results are published in both non-NASA channels and by NASA in the NASA STI Report Series, which includes the following report types:

- TECHNICAL PUBLICATION. Reports of completed research or a major significant phase of research that present the results of NASA programs and include extensive data or theoretical analysis. Includes compilations of significant scientific and technical data and information deemed to be of continuing reference value. NASA counterpart of peer-reviewed formal professional papers but has less stringent limitations on manuscript length and extent of graphic presentations.

- TECHNICAL MEMORANDUM. Scientific and technical findings that are preliminary or of specialized interest, e.g., quick release reports, working papers, and bibliographies that contain minimal annotation. Does not contain extensive analysis.

- CONTRACTOR REPORT. Scientific and technical findings by NASA-sponsored contractors and grantees.
- CONFERENCE PUBLICATION. Collected papers from scientific and technical conferences, symposia, seminars, or other meetings sponsored or cosponsored by NASA.

- SPECIAL PUBLICATION. Scientific, technical, or historical information from NASA programs, projects, and missions, often concerned with subjects having substantial public interest.

- TECHNICAL TRANSLATION. Englishlanguage translations of foreign scientific and technical material pertinent to NASA's mission.

Specialized services also include creating custom thesauri, building customized databases, organizing and publishing research results.

For more information about the NASA STI program, see the following:

- Access the NASA STI program home page at http://www.sti.nasa.gov

- E-mail your question via the Internet to help@ sti.nasa.gov

- Fax your question to the NASA STI Help Desk at 443-757-5803

- Telephone the NASA STI Help Desk at 443-757-5802

- Write to: NASA Center for AeroSpace Information (CASI) 7115 Standard Drive Hanover, MD 21076-1320 
NASA/TM-2010-216255

AIAA-2010-797

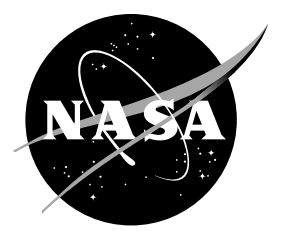

\section{An Extension of Analysis of Solar-Heated Thermal Wadis to Support Extended-Duration Lunar Exploration}

R. Balasubramaniam

National Center for Space Exploration Research, Glenn Research Center, Cleveland, Ohio

S.A. Gokoglu and K.R. Sacksteder

Glenn Research Center, Cleveland, Ohio

R.S. Wegeng

Pacific Northwest National Laboratory, Battelle Memorial Institute, Richland, Washington

N.H. Suzuki

Headquarters, Washington, DC

Prepared for the

48th Aerospace Sciences Meeting

sponsored by the American Institute of Aeronautics and Astronautics

Orlando, Florida, January 4-7, 2010

National Aeronautics and

Space Administration

Glenn Research Center

Cleveland, Ohio 44135 


\section{Acknowledgments}

The authors would like to gratefully acknowledge the valuable contributions made by H.J. Fincannon of the NASA Glenn

Research Center. We also gratefully acknowledge the support for this work by the Directorate Integration Office of the NASA Headquarters Exploration Systems Mission Directorate.

Level of Review: This material has been technically reviewed by technical management.

Available from

NASA Center for Aerospace Information

7115 Standard Drive

Hanover, MD 21076-1320
National Technical Information Service 5301 Shawnee Road Alexandria, VA 22312

Available electronically at http://gltrs.grc.nasa.gov 


\title{
An Extension of Analysis of Solar-Heated Thermal Wadis to Support Extended-Duration Lunar Exploration
}

\author{
R. Balasubramaniam \\ National Center for Space Exploration Research \\ Glenn Research Center \\ Cleveland, Ohio 44135 \\ S.A. Gokoglu and K.R. Sacksteder \\ National Aeronautics and Space Administration \\ Glenn Research Center \\ Cleveland, Ohio 44135 \\ R.S. Wegeng \\ Pacific Northwest National Laboratory \\ Battelle Memorial Institute \\ Richland, Washington 9935 \\ N.H. Suzuki \\ National Aeronautics and Space Administration \\ Headquarters \\ Washington, DC 20546
}

\begin{abstract}
The realization of the renewed exploration of the Moon presents many technical challenges; among them is the survival of lunar surface assets during periods of darkness when the lunar environment is very cold. Thermal wadis are engineered sources of stored solar energy using modified lunar regolith as a thermal storage mass that can supply energy to protect lightweight robotic rovers or other assets during the lunar night. This paper describes an extension of an earlier analysis of performance of thermal wadis based on the known solar illumination of the Moon and estimates of producible thermal properties of modified lunar regolith. The current analysis has been performed for the lunar equatorial region and validates the formerly used 1-D model by comparison of predictions to those obtained from 2-D and 3-D computations. It includes the effects of a thin dust layer covering the surface of the wadi, and incorporating either water as a phase-change material or aluminum stakes as a high thermal conductivity material into the regolith. The calculations indicate that thermal wadis can provide the desired thermal energy and temperature control for the survival of rovers or other equipment during periods of darkness.
\end{abstract}

\section{Introduction}

NASA plans to establish a permanent, manned outpost on the Moon and many systems are under development as part of NASA's plans to deploy In-Situ Resource Utilization (ISRU) capabilities at the lunar outpost. There is a need to protect the exploration systems from the extreme cold of the lunar surface. Large temperature swings are experienced at most locations on the Moon, in part because of its slow rotation rate (the diurnal cycle of the Moon is about 29.5 Earth-days long) and in part because native lunar regolith is very resistant to thermal conduction. Heat does not penetrate very deeply - approximately tens of centimeters during periods of sunlight, and as a result, temperatures typically range from a high of about $400 \mathrm{~K}$ to a low of about $100 \mathrm{~K}$. At the present time, for planning purposes, the outpost is assumed to be located in very close proximity to the south pole of the Moon, on the rim of Shackleton Crater. This location is valued largely because it experiences nearly constant sunlight (Ref. 1). Although the Sun must 


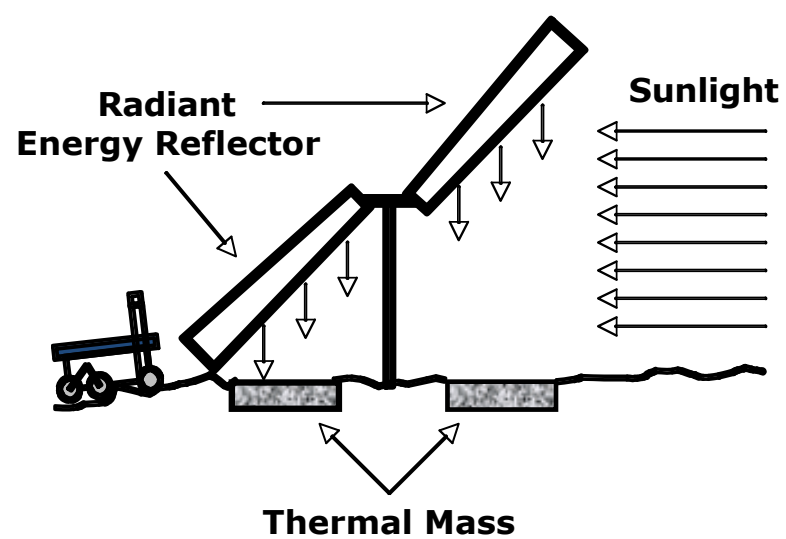

Thermal Mass

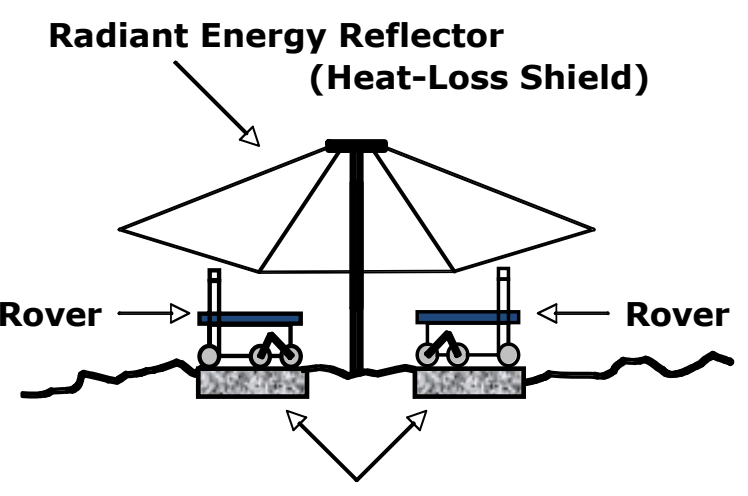

Thermal Mass

Figure 1.-The Lunar Thermal Wadi Concept. On the left, a Sun-tracking reflector directs sunlight onto a thermal mass during periods of solar illumination while rovers conduct lunar surface operations. On the right, rovers are thermally coupled to the thermal mass to stay warm during periods of darkness, and are further protected by a heat-loss shield to limit radiative losses to space.

necessarily always be at or near the horizon in this location, the small tilt of the Moon's axis with respect to the ecliptic results in short periods of darkness primarily when nearby topographic features cast shadows on this location. Presently, the longest period of complete darkness is estimated to be $52 \mathrm{hr}$.

The idea of using thermal wadis - engineered sources of heat and power - has been introduced in order to support the exploration of the Moon in several ways (Ref. 2). One aspect of its technical feasibility, viz. protection of exploration assets from the extremely cold conditions that are otherwise encountered on the lunar surface, has been shown if the thermal mass constructed on the lunar surface has sufficiently high thermal conductivity (Ref. 3). Solar energy can be used to sinter and/or melt lunar regolith, allowing it to coalesce into a continuous mass of higher thermal conductivity than native regolith. The resulting mass can store thermal energy, would experience a reduced temperature swing, and could serve as a warming pad for robotic rovers or other exploration assets during periods of darkness on the lunar surface.

The basic concept of a thermal wadi is illustrated in Figure 1 and consists of a thermal mass plus one or more energy reflectors for (a) reflecting solar energy onto the thermal mass during periods of sunlight and (b) reflecting radiant energy back to the thermal mass during periods of darkness. During periods of sunlight, thermal energy is absorbed and stored within the thermal mass. During periods of darkness the stored energy is used to provide temperature control for rovers and other exploration assets.

The thermal property values of the thermal mass are critical to the effectiveness of the thermal wadi. In its native state, lunar regolith is a poor material for thermal energy storage. The regolith, however, contains the elemental materials from which a reasonable thermal energy storage medium can be fabricated, and experiments on Earth have demonstrated that solar and/or microwave energy can enable the necessary conversion processes. Examples of regolith processing methods that can produce thermal masses with improved thermal properties include: compacting and sintering (Ref. 4), melting and solidification of processed or unprocessed regolith, inclusion of materials with high thermal conductivity and/or high thermal capacity, and chemically reducing regolith, by thermochemical or electrochemical means (Ref. 5), to produce a metal-enriched product. Several technical issues must be resolved in order to show that thermal wadis can be a valuable adjunct element of the lunar surface architecture, including whether thermal mass material can be readily produced at reasonable cost on the lunar surface.

In our previous work, we presented a 1-D model formulation, details of the thermal analysis, and results for various wadi concepts to determine the temperature of the thermal mass (Ref. 3). Our objective was to analyze the extent to which a thermal wadi can provide temperature control for a robotic rover based on several simplified configurations of operational hardware and modifications to the native regolith for creating the wadi thermal mass. As the wadi surface is the simplest interface to any hardware the wadi would support during periods of lunar darkness, the surface temperature has been especially of interest. 
In this paper, we first validate our previous 1-D analysis by comparing its surface temperature predictions to those obtained from 2-D and 3-D computations for various aspect ratios of the wadi dimensions. We explore the effect of a thin layer of dust covering the surface of the wadi on reducing temperature swings. The effect of incorporating a phase-change material, like water, into the regolith is studied to expand its thermal capacity. Finally, the effect of incorporating aluminum stakes into the regolith is considered to increase the penetration depth of thermal energy. These possible approaches to enhance the performance of thermal wadis are discussed relative to their technical feasibilities.

\section{Nomenclature}

$\begin{array}{ll}\text { AR } & \text { Aspect ratio } \\ \mathrm{t} & \text { Time, } \mathrm{hr} \\ \mathrm{PCM} & \text { Phase-change material } \\ \mathrm{T} & \text { Temperature of the wadi surface, } \mathrm{K} \\ \mathrm{T}_{\max } & \text { Maximum surface temperature, } \mathrm{K} \\ \mathrm{T}_{\min } & \text { Minimum surface temperature, } \mathrm{K}\end{array}$

\section{Previous 1-D Work}

We assumed that a 1-D analysis was sufficient in our earlier work considering that (1) the depth of the wadi would be shallow compared to its lateral extent for ease of construction, and (2) its thermal conductivity would be much larger than that of native regolith. Under these circumstances, heat transfer would be primarily in the downward direction within the bulk of the wadi and lateral heat loss to the surrounding regolith would be negligible.

Our thermal model of the wadi is similar to the Wesselink model of thermal energy transfer in planetary regolith (Refs. 6 and 7). In this model, thermal energy transport beneath the surface is solely by conduction. Radiative heat transfer is allowed only from the surface into space. The absorptivity of the wadi surface was assumed to be constant and equal to 0.9 over the wavelength spectrum of the incident light. The native emissivity of the wadi surface was also assumed to be a constant and equal to 0.9 in the wavelength spectrum of the emitted radiation (infra-red region). We assumed that the effect of the radiation shield used during the night to reduce the radiative loss from the wadi surface can be represented by an effective surface emissivity of 0.25 . The energy supplied from the surface of the wadi to a rover to keep it warm during the lunar night is estimated to be $25 \mathrm{~W} / \mathrm{m}^{2}$. In formulating the mathematical model, the heat flux balance at the surface of the wadi was therefore written as $\mathrm{q}_{\text {cond }}=\mathrm{q}_{\mathrm{abs}}-$ $\mathrm{q}_{\mathrm{rad}}-\mathrm{q}_{\mathrm{rov}}$, where $\mathrm{q}_{\mathrm{cond}}$ is the flux of energy supplied to and extracted from the bulk of the wadi by conductive heat transfer, $\mathrm{q}_{\mathrm{abs}}$ is the solar flux absorbed by the wadi surface, $\mathrm{q}_{\mathrm{rad}}$ is the radiative heat flux emitted by the surface, and $\mathrm{q}_{\mathrm{rov}}$ is the heat flux supplied by the wadi surface to the rover at night.

One-dimensional simulations were previously performed at two locations: (1) near the lunar equator, where the solar illumination of the surface can be considered periodic and similar over wide areas, and (2) a single selected site near the lunar south pole, where the illumination is quite irregular, but considered a promising site for the planned lunar outpost. The solar illumination at the lunar pole is based on the analysis of Fincannon (Ref. 8). While the Sun-tracking solar reflector shown in Figure 1 could be considered optional in the equatorial sites, it is essential near the poles to heat the wadi adequately.

When the solar peak heat flux of $1300 \mathrm{~W} / \mathrm{m}^{2}$ is applied then the surface temperatures get very close to the theoretical maximum of $389 \mathrm{~K}$ (assuming surface emissivity of 0.9 ). The maximum surface temperatures was lowered to the touch temperature levels by reducing the peak solar heat flux to $600 \mathrm{~W} / \mathrm{m}^{2}$ while not sacrificing as much on the minimum temperatures for the survival of the lunar assets over periods of darkness. The results from our earlier 1-D analysis are shown in Figure 2 for a 50-cmdeep basalt wadi with a Sun-tracking reflector and nighttime heat-loss shield when the maximum solar flux is reduced to $600 \mathrm{~W} / \mathrm{m}^{2}$ and 25 of heat is supplied to a rover (a) for the equatorial (Fig. 2(a) and (b) for the polar Fig. 2(b)) cases. The maximum surface temperatures are reduced to 319 and $320 \mathrm{~K}$ (as 

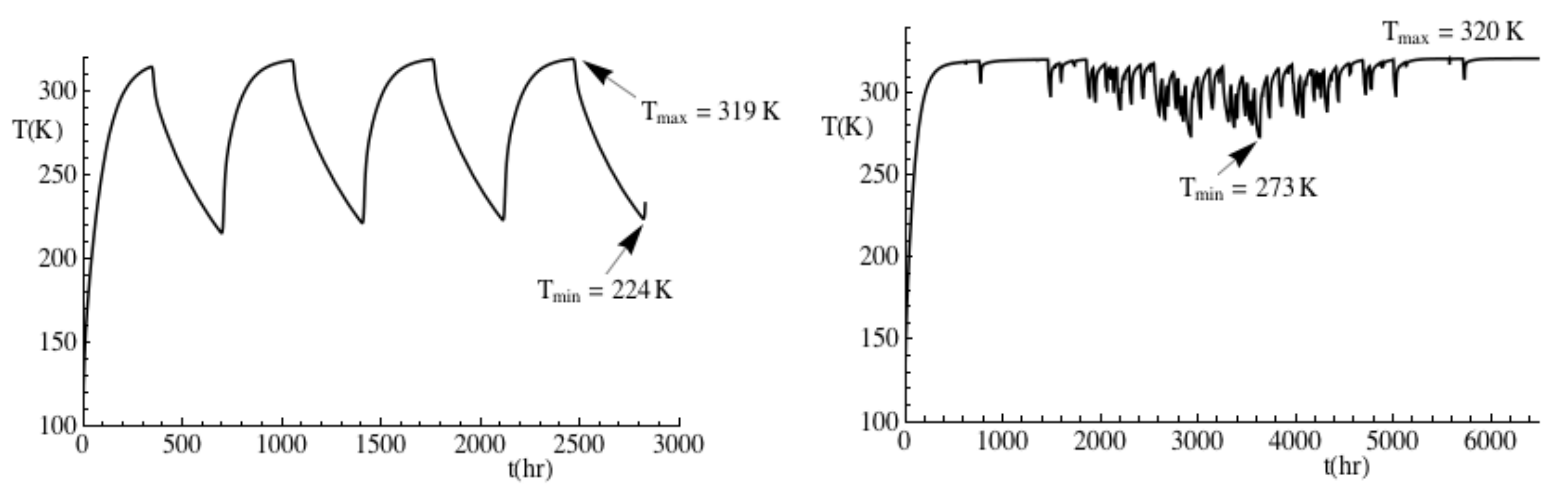

Figure 2.-One-dimensional predictions of surface temperature versus time for a 50-cm-deep wadi at (a) equatorial location and (b) polar site; surface temperature versus time.

compared to the touch temperature of $318 \mathrm{~K}$ ) while the minimum surface temperatures are at acceptable levels of 224 and $273 \mathrm{~K}$ (relative to the limiting temperature of $223 \mathrm{~K}$ we picked for electronic components) for the equatorial and polar sites, respectively.

\section{Validation of 1-D Analysis}

The validity of the $1-\mathrm{D}$ analysis is checked by employing the commercial CFD package COMSOL and constructing the corresponding 2-D and 3-D cases of the same thermal model described above. For comparison purposes, we focus only on locations near the equator, and the validation of the 1-D model is conducted only under the conditions given in Figure 3(a), which is referred to as the nominal case hereafter. Hence, the nominal case is defined as: a 50-cm-deep wadi with the thermal properties of basalt rock; equatorial location with a Sun-tracking reflector (i.e., a square wave flux profile), but maximum solar flux decreased from 1300 to $600 \mathrm{~W} / \mathrm{m}^{2}$, a heat-loss-limiting shield covering the wadi and the rover only during the periods of darkness (i.e., the effective emissivity of the wadi surface is reduced from its daytime value of 0.9 to its nighttime value of 0.25 during the periods of darkness); and a rover drawing $25 \mathrm{~W} / \mathrm{m}^{2}$ heat from the wadi only during the periods of darkness.

For the 2-D cases, the width-to-depth aspect ratio of the thermal wadi is varied between two and one. Note that the larger this aspect ratio the more is the justification for 1-D analysis, so the validation tests are conducted under relatively stringent aspect ratios close to unity. For the 3-D cases, the length of the wadi is varied the same as its width, so the length-to-depth aspect ratios are also kept the same as with respect to the width. Note that the 2-D (or 3-D) cases can be computationally reduced to 1-D analyses by applying no-heat-flux boundary conditions along the depth side (or surface) of the wadi. For more realistic 2-D (or 3-D) cases, we included a 20-cm-thick native regolith layer surrounding the sides (or surfaces) of the wadi (see Figures 3(a) and (b) for typical 2-D and 3-D computational domains, respectively). The outer sides (or surfaces) of the native regolith are assumed to be thermally insulated; i.e., no-heat-flux boundary conditions. This approach is consistent with our earlier 1-D analysis where the bottom of the wadi was assumed to be in contact also with 20-cm-deep native regolith the depth of which was determined to be sufficient. The temperature and heat flux across the wadi-regolith interfaces are taken to be continuous, as was also done for $1-\mathrm{D}$ cases.

It was demonstrated in our earlier 1-D analysis that periodic steady-state surface temperature conditions for most cases are reached within a few diurnal cycles (Ref. 3). The surface temperature profiles reported below are obtained after periodic steady-state conditions are reached at $\mathrm{t}=4242.4 \mathrm{hr}$ (i.e., the end of the sixth cycle). Figure 4(a) demonstrates the variation of the surface temperature of a 2-D wadi along its width under nominal conditions for width-to-depth aspect ratios of one and two. The variation is smaller when the aspect ratio is larger, as expected. Even for the aspect ratio of unity, the maximum variation (between the center and the two edges) is less than $0.5 \mathrm{~K}$. The corresponding surface temperature prediction for the $1-\mathrm{D}$ nominal case is always less than $2 \mathrm{~K}$ apart than even the more 


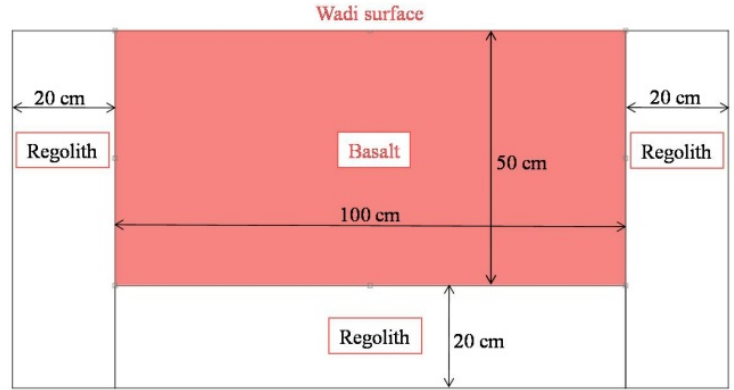

(a)

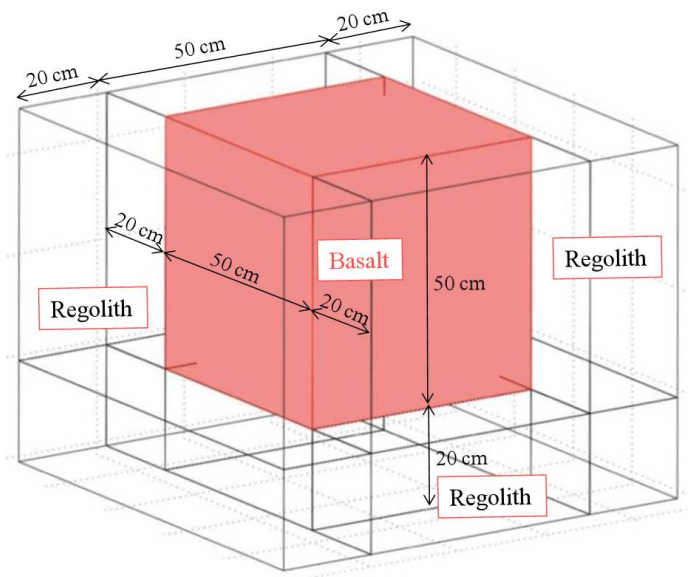

(b)

Figure 3.--Representative computational domains of a thermal wadi constructed using COMSOL: (a) 2-D, width-to-depth aspect ratio of two, and (b) 3-D, width-to-depth and length-to-depth aspect ratios of one.

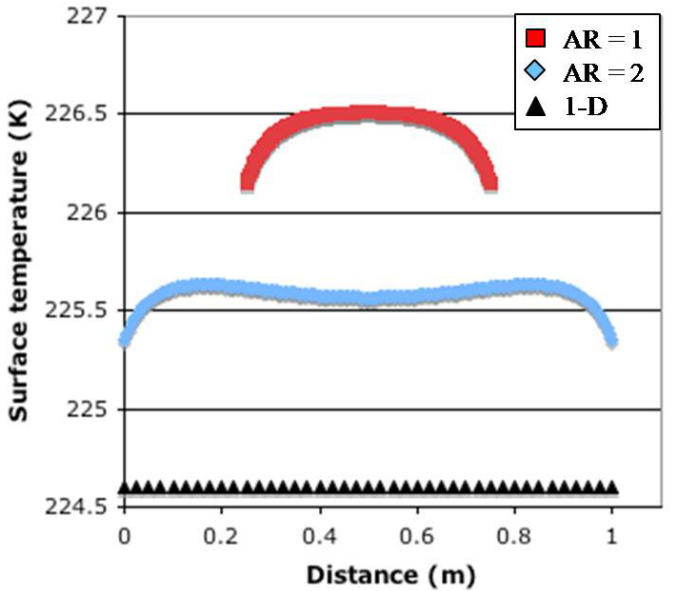

(a)

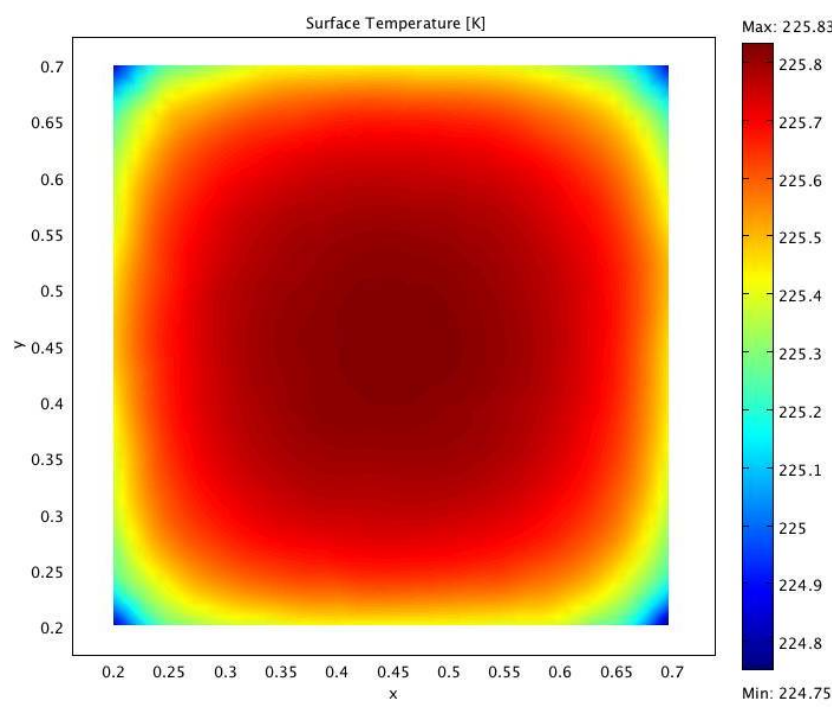

(b)

Figure 4.-Surface temperature variation of (a) 2-D wadi for width-to-depth aspect ratio of one and two as compared to 1-D prediction and (b) 3-D wadi for width-to-depth and length-to-depth aspect ratios of one.

stringent aspect ratio case of unity, and is within $1 \mathrm{~K}$ of the aspect ratio case of two. Figure 4(b) demonstrates the variation of surface temperature obtained from a 3-D calculation for which the both the width-to-depth and length-to-depth aspect ratios are unity. The maximum variation (between the center and the four corners) is about $1 \mathrm{~K}$, and the temperature is quite uniform over the entire surface area. The maximum surface temperature obtained from the $3-\mathrm{D}$ calculation is $225.8 \mathrm{~K}$ as compared to $224.6 \mathrm{~K}$ of the $1-\mathrm{D}$ prediction.

As the surface temperature is periodically changing, the difference between the 1-D prediction and the $2-\mathrm{D}$ or $3-\mathrm{D}$ calculations also varies with time. The variation of this difference is shown in Figure 5, where $\Delta \mathrm{T}_{\mathrm{s}}$ is obtained by subtracting the calculated surface temperature at the center of either the 2-D or $3-\mathrm{D}$ case from the one predicted by the 1-D analysis over the first six diurnal cycles. The differences get smaller with time and would likely become quite small by the time the periodic steady-state conditions are reached for many more cycles. Each problem set-up takes different number of cycles to reach steadystate conditions depending on dimensionality and aspect ratios; in the sixth cycle, the average difference for 3-D (the worst case) is less than approximately $3 \mathrm{~K}$. 


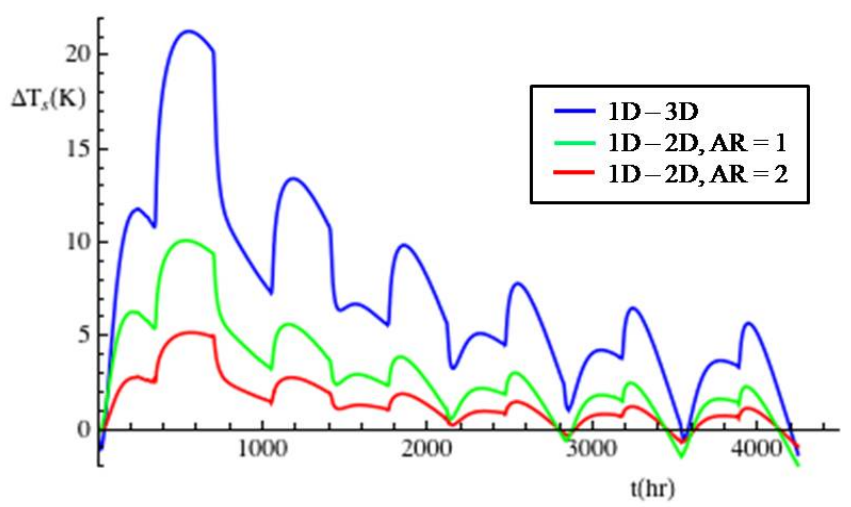

Figure 5.-The difference between the surface temperatures predicted by 1-D and by 2-D or 3-D at the center point of the surface with respect to time.

These 2-D and 3-D computations demonstrate that, provided the width and length of the wadi are at least as long as its depth, $1-\mathrm{D}$ simulations of the wadi temperatures are sufficiently accurate and the 1-D results reported in our earlier studies (Ref. 3) are valid.

\section{Effect of Dust Covering the Wadi Surface}

A potential issue of concern is the effect of dust covering the surface of the wadi. It is well known that dust is ubiquitous on the Moon. Assuming that the thermal properties of dust (that we regard as fine particles of lunar regolith) are the same as those of native regolith, one can infer from our earlier 1-D calculations that a surface dust layer in excess of $20 \mathrm{~cm}$ (of the order of the thermal penetration distance in native regolith) would render the wadi to be completely dysfunctional even when a maximum solar flux of $1300 \mathrm{~W} / \mathrm{m}^{2}$ (vs. $600 \mathrm{~W} / \mathrm{m}^{2}$ used for our nominal case) illuminates the surface. Having demonstrated the validity of the 1-D calculations, we studied the influence of various dust-layer thicknesses covering the wadi surface by using the $1-\mathrm{D}$ analysis. The same mathematical formalism used to accommodate a regolith layer below the wadi (i.e., continuous temperature and heat flux across the wadi-regolith interface) is employed to extend the regolith layer above the wadi.

Figure 6(a) shows the cyclic variation of the maximum and minimum surface temperature of the wadi that is in contact with dust (and not the temperature at the top of the dust layer that is exposed to free space) for dust-layer thicknesses up to $10 \mathrm{~mm}$. Especially for a dust-layer thickness of $5 \mathrm{~mm}$ or more, we see that wadi surface has a smaller temperature swing during the lunar diurnal cycle compared with a situation without any dust. Dust layers thicker than a few millimeters take more than four diurnal cycles to reach periodic steady-state conditions. Figure 6(b) depicts the minimum and maximum steady-state temperatures of both the wadi surface (dust-wadi interface) and the dust surface exposed to solar illumination. The first observation is that the maximum and minimum wadi temperatures (green) are confined in-between the corresponding dust temperatures (red and blue). Secondly, the swings between the maximum and minimum wadi temperatures get smaller as the dust layer gets thicker. The wadi surface maximum temperature gets smaller with increasing dust-layer thickness while its minimum temperature appears to be insensitive to the dust-layer thickness. For the dust, however, while the surface maximum temperature remains relatively flat with increasing thickness, the minimum temperature keeps dropping, since the conduction of heat from the underlying wadi gets harder as the wadi gets further buried.

The dust layer acts to shield the wadi surface from the environment at both temperature extremes. It appears that a dust layer with thickness of a few millimeters does not degrade the performance of the wadi, and might actually help mitigate the temperature swing during the diurnal cycle. 


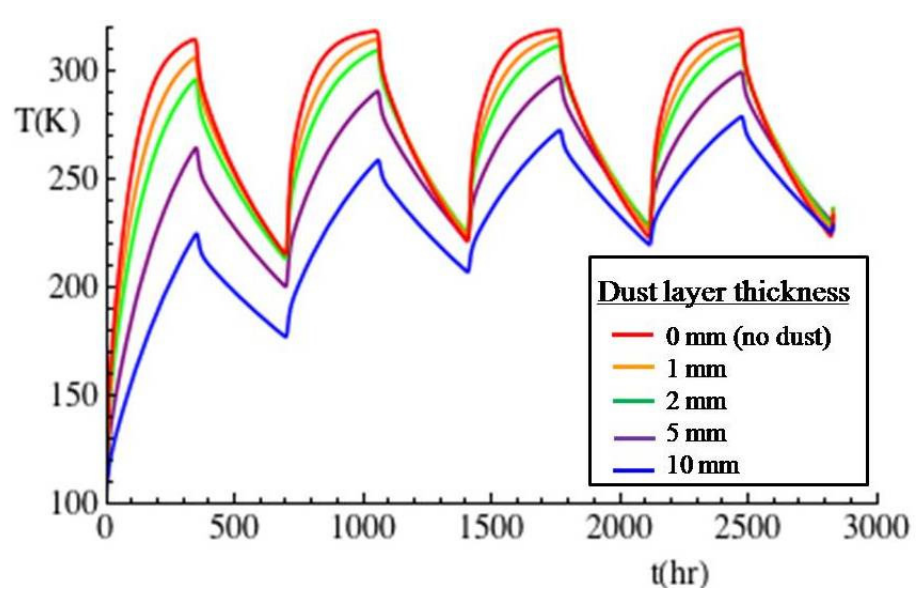

(a)

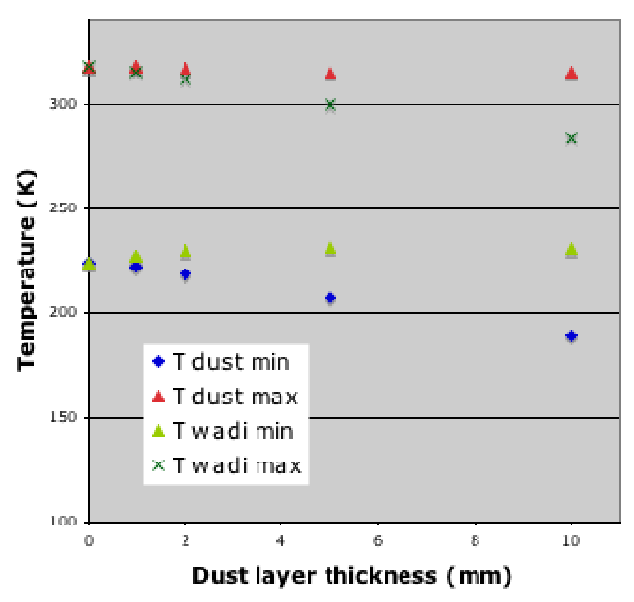

(b)

Figure 6.-Effect of dust coverage on (a) cyclic variation of dust-wadi interface temperature, and (b) the minimum and maximum steady-state temperatures of dust surface and dust-wadi interface.

\section{Effect of Using a Phase-Change Material}

Within the bulk of the wadi, there is a balance between energy storage (due to sensible heat) and energy transfer by conduction. In an attempt to improve the thermal properties of the wadi, we considered using a phase-change material. It is expected that the surface temperature swings would be reduced and the energy storage capacity would be augmented by utilizing the latent heat of fusion of the phase-change material.

The thermal properties of water and its potential availability on the Moon make it an attractive thermal mass to consider as a phase-change material. Instead of incorporating limited quantities of water into a basalt wadi, we considered replacing basalt completely by water in this study, thereby eliminating the need to fabricate a thermal mass from the lunar regolith.

Naturally, water needs to be kept in a container to prevent its flow as a liquid. There would inevitably be a volume filled with saturated water vapor inside the container, and the temperatures need to be maintained below levels which would induce boiling and convert all liquid into vapor. If we keep the container temperature cooler than the touch temperature of $318 \mathrm{~K}$ then the pressure of this saturated "bubble", which is the same as the vapor pressure of water at the prevailing temperature, would be smaller than about $72 \mathrm{mmHg}\left(\sim 0.1 \times 10^{5}\right.$ Pascals) (Ref. 9). At the theoretical maximum temperature of $389 \mathrm{~K}$ mentioned before, the pressure of the bubble would reach about $1312 \mathrm{mmHg}\left(\sim 1.75 \times 10^{5}\right.$ Pascals). The container has to be strong enough to withstand these pressure levels, depending on the application.

The physics of phase change is incorporated into the formulation of the 1-D model. The variations of the temperature at the surface of water exposed to solar illumination and at the bottom water-regolith interface are calculated over a few diurnal cycles under nominal conditions. Figures 7(a) and (b) show the results for 20 and 50-cm-deep water, respectively. While the surface steady-state temperatures are reached in three cycles for both cases, it takes longer for the bottom temperatures to reach steady state. The phase-change phenomenon can be observed by the flat green lines at the water-regolith interface. The relative position of the blue and green curves indicates the interior direction of heat flow and the contribution of the latent heat. It can be seen that the temperature of the entire mass is relatively uniform during the single-phase heating (liquid water) and cooling (ice) of the material due to the high thermal conductivity. Considering that the minimum surface temperature for a 50 -cm-deep basalt wadi is $224 \mathrm{~K}$ (see Fig. 2(a)), 20-cm-deep water results in a cooler minimum temperature of little over $210 \mathrm{~K}$ (see Fig. 7(a)), and hence, is not deep enough relative to the $50-\mathrm{cm}$-deep basalt wadi despite the thermal capacity gain by its latent heat. The fact that the green curves increase or decrease in temperature from 

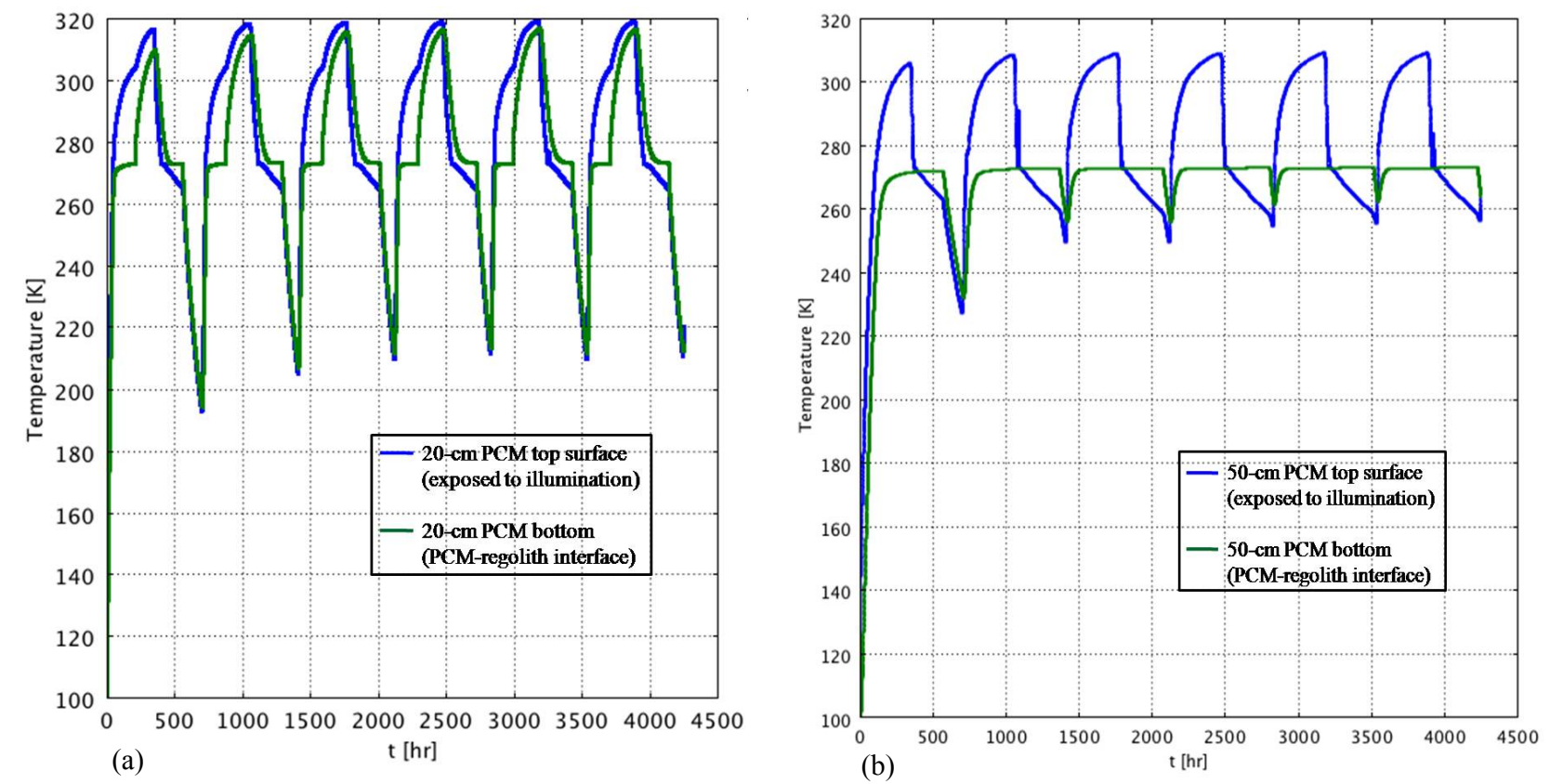

Figure 7.-Cyclic variation of top and bottom temperatures of phase-change material (water) under nominal conditions: (a) 20-cm-deep water, and (b) 50-cm-deep water.

$273 \mathrm{~K}$ indicates that all of the 20 -cm-deep water melts and freezes completely during the diurnal cycle. When the depth of water is increased to $50 \mathrm{~cm}$ (see Fig. 7(b)), the minimum surface temperature improves up to near $260 \mathrm{~K}$, and the maximum surface temperature improves down to about $310 \mathrm{~K}$ (from $319 \mathrm{~K}$ ). The water-regolith interface temperature (the green curve) mostly remains at the phase-change temperature of $273 \mathrm{~K}$ with only a brief fall below the freezing, but no rise above the melting point. Thus, the 50-cm-deep water layer does not completely melt during the lunar day, and is completely frozen during the lunar night. This means that the performance of the thermal mass can still be improved with water depths larger than $50 \mathrm{~cm}$, which would eliminate the fall below the freezing point and somewhat reduce the maximum surface temperature. However, there is ultimately a trade-off, depending on application requirements, between the marginal temperature benefit versus the fabrication difficulty and needed additional resource.

\section{Effect of Incorporating Thermally Conductive Stakes}

Similar to the idea of using phase-change materials, the performance of the thermal mass can be enhanced by incorporating high thermal conductivity materials. Faster conduction of heat into the thermal mass via the use of, say, metal stakes (that act as fins) would allow energy to penetrate deeper, and hence, increase thermal storage capacity of the wadi and mitigate the surface temperature swings to benefit the rovers. We explored the use of aluminum stakes inserted into native regolith to eliminating the need to fabricate a wadi from the lunar regolith.

The results would certainly depend on the dimensions, shapes, number densities and volumetric distributions of the stakes in the native regolith. The ratio of the heat transfer surface area of the Al stakes to the volume of the regolith is a key parameter. Therefore, we have constructed a 3-D model to analyze this problem. As an example case, we have used Al stakes of 5 by $5 \mathrm{~cm}$ bases and (initially) $50 \mathrm{~cm}$ lengths which are vertically inserted into the regolith and uniformly distributed at 25 stakes per square meter. In order to distribute the heat efficiently over the surface and provide a uniform-temperature 

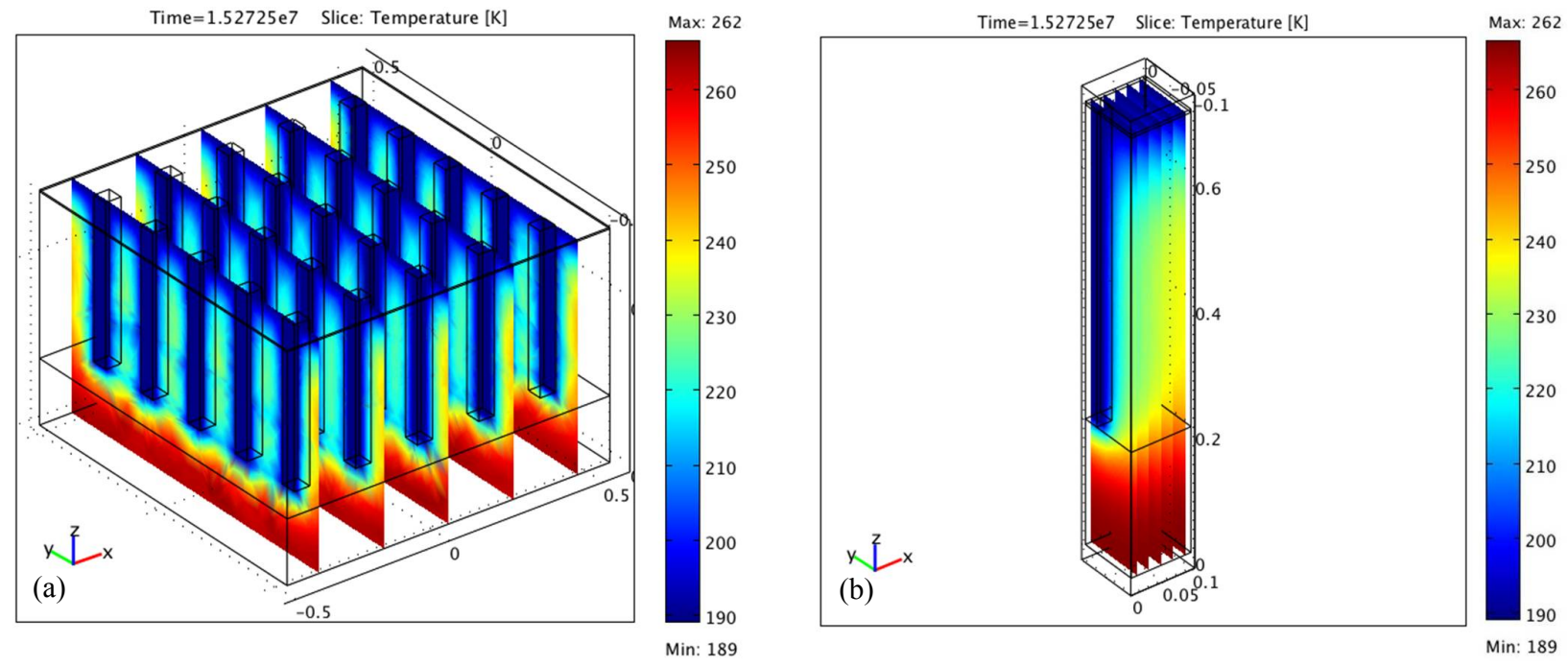

Figure 8.-The effect of 5 by 5 by $50 \mathrm{~cm} \mathrm{Al} \mathrm{stakes,} \mathrm{distributed} \mathrm{vertically} \mathrm{and} \mathrm{uniformly} \mathrm{at} 25 \mathrm{stakes} / \mathrm{m}^{2}$, and a 5-mm-thick Al cover plate on wadi temperature under nominal conditions: (a) 3-D steady-state temperature distribution shown by 5 slices, and (b) temperature distribution of a computational unit volume ( 5 slices).
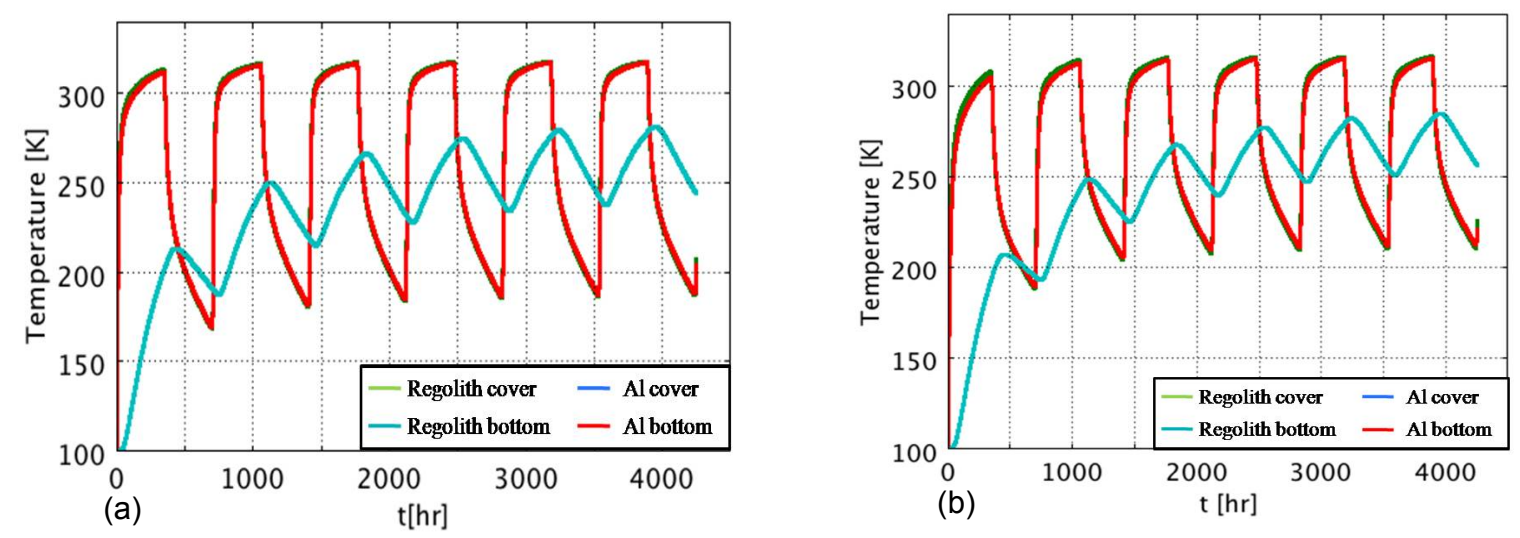

Figure 9.- The cyclic variation of Al cover plate, Al stake, and regolith temperatures under nominal conditions:

(a) 5 by 5 by $50 \mathrm{~cm} \mathrm{Al} \mathrm{stakes,} \mathrm{and} \mathrm{(b)} 5$ by 5 by $80 \mathrm{~cm} \mathrm{Al} \mathrm{stakes.}$

interface for the rover, we have also included a 5-mm-thick Al cover plate stretching over the entire wadi, sitting on top of the stakes as well as the regolith. The surface emissivity of the Al cover plate is taken to be the same as those used for the regolith during the daytime and nighttime, respectively.

Figure 8(a) depicts the resulting 1 by $1 \mathrm{~m}$ surface area by $50-\mathrm{cm}$-deep unit volume wadi structure, including a $20-\mathrm{cm}$-deep underlying native regolith layer used in the computations. Such a definition allows the 3-D problem to be reduced to an analysis of a self-repeating unit volume of smaller dimensions, thereby, simplifying the computational burden. The unit volume consists of a corner section in depth taken up by a quarter of a stake and the rest occupied by the regolith (Fig. 8(b)).

The 3-D calculations of this thermal mass under nominal conditions reach approximate steady-state conditions in six diurnal cycles. Figure 9(a) shows the cyclic variation of temperatures in different colors taken at the center point of each of the indicated locations for 50-cm-long stakes. The end of the sixth diurnal cycle $(\sim 4242.4 \mathrm{hr})$ is the end of the nighttime as the Sun is rising; and therefore, the surface temperature of the regolith is quite cold. Note that the thermally conductive Al cover plate is able to provide a uniform temperature on the surface and that there is no discernable difference between the Alcover (blue), regolith-cover (green), and Al-bottom (red) temperatures. Even though the surface reaches 
its coldest temperature of about $189 \mathrm{~K}$ at this point in time (see Figs. 8(a) and (b)), the deeper regions are quite warmer during both daytime and nighttime cycles as indicated by the regolith-bottom temperature (aqua) in Figure 9(a). This demonstrates that native regolith has good energy storage capability, if conductive stakes are employed to transport the heat to deeper regions within the regolith. With a square wave daytime solar heat flux of $600 \mathrm{~W} / \mathrm{m}^{2}$ illuminating the Al cover plate on the wadi surface, the regolith temperature beneath the wadi structure is approximately $262 \mathrm{~K}$. This is a substantial improvement in comparison to the case of sinusoidal flux with a higher peak value of $1300 \mathrm{~W} / \mathrm{m}^{2}$ for which our prior calculations show that the regolith temperature beyond a penetration depth of approximately $20 \mathrm{~cm}$ is $232 \mathrm{~K}$. The minimum surface temperature of $189 \mathrm{~K}$ for 50 -cm-long stakes is colder, however, than would be desired for electronic components. One way to improve on the minimum temperature is to increase the length of the stakes.

Figure 9(b) shows the level of improvement on the minimum surface temperature when the length of the $\mathrm{Al}$ stakes is increased from 50 to $80 \mathrm{~cm}$, but still with a 20-cm-deep underlying native regolith layer. The minimum surface temperature rises from $189 \mathrm{~K}$ to about $215 \mathrm{~K}$, as indicated by the nearly identical Al-cover (blue), regolith-cover (green), and Al-bottom (red) temperatures. There is no noticeable change in the maximum surface temperature since it is mostly governed by the solar flux and the emissivity of the $\mathrm{Al}$ cover plate, both of which are unchanged. As mentioned above, Al cover plate and Al stakes remain isothermal throughout the thermal cycles due to the high thermal conductivity. Note also that the periodic regolith-bottom temperature (aqua) seems to be still rising even after the sixth cycle, demonstrating that it takes longer to reach periodic steady state for longer stakes and that the energy storage capacity of longer stakes is larger.

\section{System Level Implications}

The utility of the thermal wadi concept is intended to be more than an academic exercise. The authors have suggested previously that nighttime hardware survival on the Moon, especially in non-polar latitudes, is challenging - especially if the energy to maintain minimally acceptable temperatures of critical asset components must be carried on board. The thermal wadi is envisioned as an approach to offloading this requirement onto a simple surface infrastructure element, perhaps combined with other functions such as communications, electrical power for non-thermal functions and consumable replenishment. From an overall systems point of view, the question is not whether it is possible to build lunar surface assets that are fully self-sufficient, but whether providing simple lunar surface infrastructure elements such as the thermal wadi makes it sufficiently easier to build discrete lunar surface assets so that a greater total lunar surface capability could be deployed for the same limited resources, or further, that additional resources might appear because of improved marginal benefit from those new investments.

The evaluation of a lunar architecture, either robotic or human, using thermal wadis and other capabilities that can be provided in a distributed fashion around the lunar surface has not been performed. In support of this architecture approach, additional work is needed in the evaluation of thermal wadi design options including their use as heat-sink devices for absorbing excess heat generated during the lunar day, and the testing of various options for manufacturing thermal mass from lunar materials, including the use of boulders. Assessments of various thermal management approaches for long-lived lunar surface assets have not been performed and are needed, including comparisons between on-board versus infrastructure-supplied capability. Concepts and testing of approaches for reliable thermal interfaces between lunar surface assets and thermal wadis are needed to broaden the system level feasibility of the thermal wadi concept. As these concept developments mature, estimates of the implementation cost and mass of the various overall system configurations can emerge as a basis for architecture optimization and comparison with other approaches. 


\section{Conclusions}

The feasibility of utilizing native materials on the lunar surface to store thermal energy for the nighttime survival of valuable scientific and exploration assets has been demonstrated. The feasibility is a consequence of complementary factors: the volumetric heat capacity and thermal conductivity of modified lunar regolith, the intensity of unconcentrated solar energy flux at the lunar surface, and the total energy requirements for hardware survival over the duration of the cold lunar-night. Together, these factors lead to effective thermal wadi configurations that are comparable in size to the assets being protected, with engineering margin providing flexibility in the configuration of a thermal wadi to the needs of a particular asset class or lunar surface location. The current paper validates previous studies on the feasibility of thermal wadis using modified lunar regolith as the thermal mass, studies the effect of thin layers of regolith dust covering the wadi, and provides analysis of additional options for augmenting performance including phase-change materials and embedded conducting stakes. Each approach leads to a configuration that maintains temperatures within the operating range of aerospace electronics and mechanical components. Additionally, this paper has extended the notion that sufficient flexibility and engineering margin exists to regulate both the maximum and minimum temperatures of the thermal mass to meet the practical aspects of interfacing thermal masses with the valuable lunar surface assets they are intended to protect. Various options and testing of approaches for reliable thermal interfaces between lunar surface assets and thermal wadis are needed to broaden the system level feasibility of the thermal wadi concept, to enable estimation of implementation cost and overall system mass.

\section{References}

1. Wegeng, R.S., J.C. Mankins, L.A. Taylor, and G.B. Sanders, "Thermal Energy Reservoirs from Processed Lunar Regolith," 5th International Energy Conversion Engineering Conference, July, 2007.

2. Wegeng, R.S., J.C. Mankins, R. Balasubramaniam, K. Sacksteder, S.A. Gokoglu, G.B. Sanders, and L.A. Taylor, "Thermal Wadis in Support of Lunar Science \& Exploration," 6th International Energy Conversion Engineering Conference, Cleveland, Ohio, July 2008.

3. Balasubramaniam, R., Wegeng, R.S., Gokoglu, S.A., Suzuki, N., and Sacksteder, K., "Analysis of Solar-Heated Thermal Wadis to Support Extended-Duration Lunar Exploration," AIAA-2009-1339, 47th AIAA Aerospace Sciences Meeting and Exhibit, Orlando, Florida, January 2009.

4. Taylor, L.A., and Meeks, T.T., "Microwave Sintering of Lunar Soil: Properties, Theory, and Practice," Jour. Aerosp. Engr. 18, pp. 188-196, 2005.

5. Taylor, L.A., and Carrier, W.D. III, "Oxygen Production on the Moon: An Overview and Evaluation," Chapter in Resources of Near-Earth Space, pp. 69-108, Univ. of Ariz. Series, 1993.

6. Wesselink, A. "Heat Conductivity and the Nature of the Lunar Surface Material," Bull. Astron. Inst. Neth. 10, 351-363, 1948.

7. Yaeger, J.C., "Conduction of Heat in a Solid with Periodic Boundary Conditions, with an Application to the Surface Temperature of the Moon," Proc. Camb. Phil. Soc., 49, 355-359, 1953.

8. H.J. Fincannon, "Lunar Polar Illumination for Power Analysis," AIAA-2008-5631, 6th International Energy Conversion Engineering Conference, Cleveland, Ohio, July 2008.

9. Ohe, Shuzo, "Vapor Pressure Calculation Program," http://e-data.jp/vpcal2/e/Water_cal.html, 2009. 


\begin{tabular}{|c|c|c|}
\hline \multicolumn{2}{|c|}{ REPORT DOCUMENTATION PAGE } & $\begin{array}{l}\text { Form Approved } \\
\text { OMB No. 0704-0188 }\end{array}$ \\
\hline \multicolumn{3}{|c|}{ 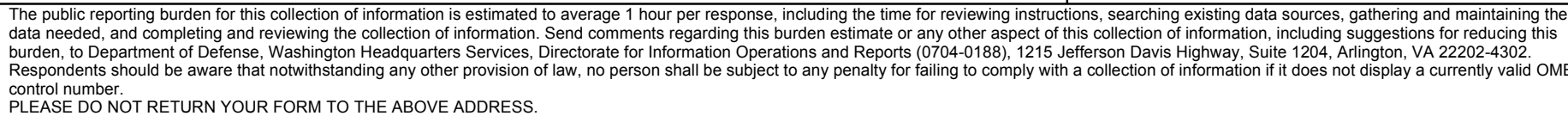 } \\
\hline $\begin{array}{l}\text { 1. REPORT DATE (DD-MM-YYYY) } \\
01-04-2010\end{array}$ & $\begin{array}{l}\text { 2. REPORT TYPE } \\
\text { Technical Memorandum }\end{array}$ & 3. DATES COVERED (From - To) \\
\hline \multirow{3}{*}{\multicolumn{2}{|c|}{$\begin{array}{l}\text { 4. TITLE AND SUBTITLE } \\
\text { An Extension of Analysis of Solar-Heated Thermal Wadis to Support Extended-Duration } \\
\text { Lunar Exploration }\end{array}$}} & 5a. CONTRACT NUMBER \\
\hline & & 5b. GRANT NUMBER \\
\hline & & 5c. PROGRAM ELEMENT NUMBER \\
\hline \multirow{3}{*}{\multicolumn{2}{|c|}{$\begin{array}{l}\text { 6. AUTHOR(S) } \\
\text { Balasubramaniam, R.; Gokoglu, S., A.; Sacksteder, K., R.; Wegeng, R., S.; Suzuki, N., H. }\end{array}$}} & 5d. PROJECT NUMBER \\
\hline & & 5e. TASK NUMBER \\
\hline & & $\begin{array}{l}\text { 5f. WORK UNIT NUMBER } \\
\text { WBS } 075585.01 .06 .01 .03 .03\end{array}$ \\
\hline \multicolumn{2}{|c|}{$\begin{array}{l}\text { 7. PERFORMING ORGANIZATION NAME(S) AND ADDRESS(ES) } \\
\text { National Aeronautics and Space Administration } \\
\text { John H. Glenn Research Center at Lewis Field } \\
\text { Cleveland, Ohio 44135-3191 }\end{array}$} & $\begin{array}{l}\text { 8. PERFORMING ORGANIZATION } \\
\text { REPORT NUMBER } \\
\text { E-17241 }\end{array}$ \\
\hline \multirow{2}{*}{\multicolumn{2}{|c|}{$\begin{array}{l}\text { 9. SPONSORING/MONITORING AGENCY NAME(S) AND ADDRESS(ES) } \\
\text { National Aeronautics and Space Administration } \\
\text { Washington, DC 20546-0001 }\end{array}$}} & $\begin{array}{l}\text { 10. SPONSORING/MONITOR'S } \\
\text { ACRONYM(S) } \\
\text { NASA }\end{array}$ \\
\hline & & $\begin{array}{l}\text { 11. SPONSORING/MONITORING } \\
\text { REPORT NUMBER } \\
\text { NASA/TM-2010-216255 }\end{array}$ \\
\hline \multicolumn{3}{|c|}{$\begin{array}{l}\text { 12. DISTRIBUTION/AVAILABILITY STATEMENT } \\
\text { Unclassified-Unlimited } \\
\text { Subject Categories: } 29 \text { and } 34 \\
\text { Available electronically at http://gltrs.grc.nasa.gov } \\
\text { This publication is available from the NASA Center for AeroSpace Information, 443-757-5802 }\end{array}$} \\
\hline
\end{tabular}

\section{SUPPLEMENTARY NOTES}

\section{ABSTRACT}

The realization of the renewed exploration of the Moon presents many technical challenges; among them is the survival of lunar surface assets during periods of darkness when the lunar environment is very cold. Thermal wadis are engineered sources of stored solar energy using modified lunar regolith as a thermal storage mass that can supply energy to protect lightweight robotic rovers or other assets during the lunar night. This paper describes an extension of an earlier analysis of performance of thermal wadis based on the known solar illumination of the Moon and estimates of producible thermal properties of modified lunar regolith. The current analysis has been performed for the lunar equatorial region and validates the formerly used 1-D model by comparison of predictions to those obtained from 2-D and 3-D computations. It includes the effects of a thin dust layer covering the surface of the wadi, and incorporating either water as a phase-change material or aluminum stakes as a high thermal conductivity material into the regolith. The calculations indicate that thermal wadis can provide the desired thermal energy and temperature control for the survival of rovers or other equipment during periods of darkness.

\section{SUBJECT TERMS}

Lunar surface systems; Energy storage; Solar thermal heating; Lunar environment; Vision for space exploration; Lunar architecture

\begin{tabular}{|c|c|c|c|c|c|}
\hline \multicolumn{3}{|c|}{ 16. SECURITY CLASSIFICATION OF: } & \multirow{2}{*}{$\begin{array}{l}\text { 17. LIMITATION OF } \\
\text { ABSTRACT } \\
\text { UU }\end{array}$} & \multirow{2}{*}{$\begin{array}{l}\text { 18. NUMBER } \\
\text { OF } \\
\text { PAGES } \\
17\end{array}$} & \multirow{2}{*}{$\begin{array}{l}\text { 19a. NAME OF RESPONSIBLE PERSON } \\
\text { STI Help Desk (email:help@sti.nasa.gov) } \\
\text { 19b. TELEPHONE NUMBER (include area code) } \\
\text { 443-757-5802 }\end{array}$} \\
\hline $\begin{array}{l}\text { a. REPORT } \\
U\end{array}$ & $\begin{array}{l}\text { b. ABSTRACT } \\
\text { U }\end{array}$ & $\begin{array}{l}\text { c. THIS } \\
\text { PAGE } \\
\text { U }\end{array}$ & & & \\
\hline
\end{tabular}



